\title{
Glutamate Dehydrogenase Deficiency in Machado-Joseph Disease
}

\author{
A. Gonçalves, C. Oliveira, M.A. Ferro, M. Dinis and L. Cunha
}

\begin{abstract}
We studied the activity of glutamate dehydrogenase (GDH) in leukocytes from 23 patients with dominantly inherited ataxia. All the patients were assessed with a rating scale for ataxias and met the clinical criteria for the diagnosis of Machado-Joseph disease. The mean age of onset of symptoms was 37.8, SD 13.4 years and the duration of the disease was 7.4, SD 4.9. Leukocyte GDH activity was significantly decreased $(p<0.001)$ when compared to 20 normal controls. These data extend previous reports indicating that a GDH deficiency is present in peripheral tissues from some patients with spinocerebellar degenerations. Furthermore, this study suggests that a genetic deficiency of GDH may underlie some forms of dominant ataxias; this deficiency may be marked in patients with Machado-Joseph disease and is not specific for any type of multiple system atrophy.
\end{abstract}

RÉSUMÉ: Déficit en glutamate déshydrogénase dans la maladie de Machado-Joseph. Les auteurs rapportent les résultats de l'étude de l'activité enzymatique de la glutamate déshydrogénase (GDH) dans les leucocytes de 23 patients atteints d'ataxie héréditaire à transmission autosomale dominante. Tous les patients ont été soumis à un examen neurologique standardisé pour évaluer l'ataxie et rencontraient les critères diagnostiques de la maladie de MachadoJoseph. L'âge moyen de début des symptômes était de $37.8( \pm 13.4)$ ans et la durée de la maladie était de $7.4( \pm 4.9)$ ans. L'activité leucocytaire de la GDH était diminuée de façon significative $(p<0.001)$ comparée à 20 contrôles normaux. Ces résultats appuient des études antérieures qui suggèrent que certains patients atteints d'une dégénérescence spinocérébelleuse ont une diminution de cet enzyme dans leurs tissus périphériques. De plus, cette étude suggère qu'une déficience génétique en GDH peut être à la base de certaines formes d'ataxies dominantes, qu'elle peut être importante chez la plupart des patients atteints de la maladie de Machado-Joseph et qu'elle n'est pas spécifique à un type d'atrophie multi-systémique.

Can. J. Neurol. Sci. 1993; 20:147-150

Hereditary ataxias are a heterogeneous group of disorders showing different patterns of inheritance and various clinical and pathological abnormalities.' In contrast to some forms of recessively inherited ataxias in which enzyme defects have been reported, the primary biochemical defect in autosomal dominant ataxias is not known..$^{1.2}$ In recent years Perry et al..$^{3-6}$ have described a decrease in the GABA, aspartate and glutamate contents of the cerebellum and other regions of the brain of patients with dominantly inherited olivopontocerebellar atrophy (OPCA). Glutamate and its metabolites play an important role both in the intermediary metabolism of the brain and in chemical neurotransmission. ${ }^{7.8} \mathrm{GDH}$ is an enzyme of glutamate metabolism that catalyses the formation of glutamate upon addition of an ammonium ion group to alpha-ketoglutarate.9.10 This reaction is readily reversible, providing a mechanism for modulating the flow of alpha-ketoglutarate into either carbohydrate or nitrogen metabolism. ${ }^{9}$

Abnormal glutamate metabolism in patients with dominant ataxia," as well as a partial deficiency of GDH in fibroblasts, leukocytes or platelets from patients with this disorder have been found by some authors, ${ }^{11-13}$ but not by others. ${ }^{14-16}$ Conflicting results have also been reported in patients with other forms of ataxia as well as other multi-system degenerations. ${ }^{16-21}$ To clarify some of these problems we have studied GDH activity in leukocytes from 23 patients with dominant ataxia and 20 normal controls.

\section{Material and Methods}

\section{Patients}

Twenty-three ataxis patients ( 9 males and 14 females) from 8 families were assessed with a rating scale for ataxias composed of 81 items grouped into 7 categories (global score 83 ) $^{22}$ : 1) ataxia score including gait ataxia, Romberg sign and limb incoordination (maximum 16); 2) upper motor neuron (UMN) score, including spasticity, hyperreflexia, clonus and Babinski signs (maximum 16); 3) peripheral nerve score including decreased tendon reflexes and atrophy (maximum 16); 4) fasciculation score; 5) parkinsonian score including cogwheel rigidity and bradykinesia; 6) ophthalmoplegia score; and 7) vibration sense score. These patients came from 8 families living in the Azores Islands. The disease frequency amongst siblings, parents and 
children, was in agreement with an autosomal dominant transmission pattern in all the families. On the other hand, the disease was present at least in three generations in each family and both sexes were equally affected. None of these patients were taking anti-inflammatory drugs and clinical features were partially described in a previous paper. ${ }^{22}$ Twenty age-matched normal volunteers (nurses and doctors) served as healthy controls.

\section{Leukocyte Preparations}

Leukocyte pellets were isolated from heparinized venous blood with a modification of the method of Christlieb et al. ${ }^{23}$ Blood was collected in plastic syringes, mixed with $4 \mathrm{ml} 6 \%$ dextran solution in isotonic saline and allowed to stand in the inverted syringe at room temperature for 1 hour. The supernatant plasma was collected and centrifuged at $4^{\circ} \mathrm{C}$ for $10 \mathrm{~min}$ utes at 1500 r.p.m. The resulting leukocyte pellet was suspended in $0.5 \mathrm{ml}$ isotonic saline, and $4 \mathrm{ml}$ of $0.87 \%$ ammonium chloride was added to lyse erythrocytes. After 15 minutes the suspension was again centrifuged at 1500 r.p.m. The resulting pellet was washed twice by resuspension in $10 \mathrm{ml}$ isotonic saline at $4^{\circ} \mathrm{C}$ and recentrifuged in the same way. The cells were then quickfrozen and stored at $-80^{\circ} \mathrm{C}$.

\section{GDH Assay}

The leukocytes were disrupted by freeze-thaw cycles and homogenized in $0.05 \mathrm{M}$ triethanolamine buffer, $\mathrm{pH} 8.0$, with $0.05 \%$ Triton X-100. GDH activity was measured in duplicate, by following the oxidation of NADH spectrophotometrically. The reaction mixture contained $50 \mathrm{mM}$ triethanolamine $(\mathrm{pH}$ 8.0), $3.22 \mathrm{mM}$ EDTA, $129 \mathrm{mM} \mathrm{CH}_{3} \mathrm{COONH}_{4}, 2.5 \mu \mathrm{M}$ rotenone, $100 \mu \mathrm{M}$ NADH, $1.0 \mathrm{mM}$ ADP in a final volume of $2.6 \mathrm{ml}$. A circulating water bath was used to maintain the temperature at $25^{\circ} \mathrm{C}$, and $300 \mu \mathrm{l}$ of the leukocyte homogenate $(0.5 \mathrm{mg}$ protein) was added to the cuvette with mixing. Baseline NADH oxidation was monitored by following the decrease in absorbance at $340 \mathrm{~nm}$ during 5 minutes. GDH activity was initiated by adding $0.1 \mathrm{ml}$ of $2 \mathrm{mM}$ sodium oxoglutarate. The results were expressed in nanomoles of substrate utilized per minute per milligram of protein. Protein was measured by the method of Layne. ${ }^{24}$ Statistical analysis was performed using Student t test.

\section{RESULTS}

\section{Clinical Features}

All the patients shared the clinical features of MachadoJoseph disease ${ }^{25}$ although the same symptoms have been described in dominant OPCA. ${ }^{22}$ The age ranged from 11 to 68 years (mean 37.8, SD 13.4 years) and the duration of symptoms from 1 to 18 years (mean 7.4, SD 4.9 years). The initial manifestation was unsteadiness in walking. Later on diplopia, dysarthria and dysphagia were also common complaints. The clinical picture was dominated by ataxia in most of the patients, but upper motor neuron (UMN) signs (mean 3.8, SD 3.4) and peripheral nerve signs (mainly distal atrophy and diminished or absent tendon reflexes) (mean 4.1, SD 3.9) were also frequent. UMN signs were prominent in the cases where the disease started at younger ages. In contrast, lower motor neuron signs were more prominent at later ages. In fact cerebellar dysfunction as well peripheral nerve signs correlated positively with the age of onset and the duration of the disease, whereas correlation of UMN signs with age of onset was negative. Ophthalmoplegia, nystagmus and vibratory sense alteration were also common findings. In contrast, extrapyramidal signs were very rare. The clinical features were similar in both sexes, although muscle atrophy was less severe in female patients. Case reports will show some clinical differences between individual cases, mainly related to the age of onset of the disease.

\section{Case Reports}

Patient 1 (Family 1) - A 58-year-old female developed progressive ataxia of gait at the age of 48 years. Later on she also complained of diplopia, dysarthria, dysphagia and weight loss. On examination she was dysarthric and had severe limb and truncal ataxia. There was generalized muscle atrophy, fasciculations, hypotonia and absent deep tendon reflexes. Plantar responses were extensor. Severe external ophthalmoplegia and nystagmus on lateral gaze were also present. Vibration sense was abolished at the ankles and pain and temperature sensation were normal. There was no mental impairment.

Patient 5 (Family 1) - This 11-year-old boy first complained of gait unsteadiness at the age of 10 years. One of his brothers had a very similar disorder and both parents were affected with Machado-Joseph disease. On examination there was generalized muscle atrophy, hyperactive deep tendon reflexes with ankle clonus and bilateral Babinski signs. Limb and truncal dystonia were present. Pain and temperature sense were intact but vibration sense was diminished at the ankles. Eye movements were slightly limited and nystagmus was present. There was dysarthria and dysphagia.

Patient 7 (Family 2) - This 58-year-old female first noticed hand tremor at the age of 50 years. Later on she also complained of gait unsteadiness and diplopia. On examination there was moderate gait ataxia and dysarthria. Muscle atrophy and fasciculations were present. Deep tendon reflexes were normal in the upper limbs and abolished in the lower limbs. Plantar responses were equivocal. Mild external ophthalmoplegia and nystagmus were present. Pain and temperature sense were normal and vibration sense was diminished at the ankles.

Patient 11 (Family 4) - This 64-year-old man developed slowly progressive gait unsteadiness at age 59. Later on he also complained of diplopia, dysarthria and dysphagia. Neurological examination revealed generalized muscle atrophy, fasciculations, hypotonia and absent deep tendon reflexes. Bilateral Babinski signs were present as well as moderate gait ataxia. External ophthalmoplegia and nystagmus on lateral gaze were also present. Pain and temperature sensation were intact but vibration sense was abolished at the ankles. There were no involuntary movements or mental impairment.

Patient 18 (Family 6) - This 40-year-old woman first noticed gait instability at age 28 . In following years diplopia, dysarthria, dysphagia and clumsy hands also developed. On examination there was distal muscle atrophy, spasticity of the four limbs, hyperactive deep tendon reflexes with ankle clonus and bilateral Babinski signs. She was restricted to a wheelchair for the last 2 years. Ophthalmoplegia, nystagmus and bulging eyes were present as well as faciolingual atrophy and generalized fasciculations. Pain sensation was normal but vibration sense was absent at the ankles. There was urinary incontinence.

\section{Leukocyte GDH Activity}

The results are presented in Table 1. Mean GDH activity in 20 normal controls was $5.0, \mathrm{SD} 1.2 \mathrm{nmol} / \mathrm{min} / \mathrm{mg}$ protein (range from 3.7 to $8.6 \mathrm{nmol} / \mathrm{min} / \mathrm{mg}$ protein). Mean GDH activity in dominant ataxic patients $(2.5, \mathrm{SD} 2.6 \mathrm{nmol} / \mathrm{min} / \mathrm{mg}$ protein $)$ was $50 \%$ of the control mean. Although patients and controls overlapped, the difference between the two groups was significant ( $p$ $<0.001$ ). Two patients (one with chronic alcoholism and the other idiopathic parkinsonism associated with the ataxic syndrome) had increased GDH levels. GDH deficiency was not related to the age of onset of manifestations nor to the duration of disease, the sex of patient, or even to the clinical manifesta- 


\begin{tabular}{|c|c|c|c|c|c|c|}
\hline Patient & Sex & Family & $\begin{array}{l}\text { Age of Onset } \\
\text { (Years) }\end{array}$ & $\begin{array}{c}\text { Duration of Disease } \\
\text { (Years) }\end{array}$ & $\begin{array}{l}\text { Global Clinical } \\
\text { Score }\end{array}$ & $\begin{array}{c}\text { GDH Activity } \\
\text { (nmol/min } / \mathrm{mg})\end{array}$ \\
\hline 1 & $F$ & 1 & 48 & 10 & 43 & 0.8 \\
\hline 2 & F & 1 & 35 & 2 & 17 & 3.1 \\
\hline 3 & $\mathrm{M}$ & 1 & 40 & 8 & 21 & 1.5 \\
\hline 4 & $\mathrm{M}$ & $i$ & 39 & 13 & 27 & 0.2 \\
\hline 5 & M & 1 & 10 & 1 & 28 & 3.0 \\
\hline 6 & $M$ & 1 & 26 & 13 & 37 & 1.1 \\
\hline 7 & $\mathrm{~F}$ & 2 & 50 & 8 & 19 & 3.0 \\
\hline 8 & $\mathrm{~F}$ & 2 & 60 & 9 & 27 & 1.3 \\
\hline 9 & $\mathrm{~F}$ & 3 & 38 & 3 & 18 & 0.6 \\
\hline 10 & $\mathrm{M}$ & 4 & 57 & 12 & 36 & 0.9 \\
\hline 11 & $\mathrm{M}$ & 4 & 59 & 5 & 33 & 1.3 \\
\hline 12 & $\mathrm{~F}$ & 5 & 32 & 2 & 9 & 4.8 \\
\hline 13 & $F$ & 5 & 43 & 12 & 43 & 1.3 \\
\hline 14 & $\mathrm{~F}$ & 5 & 40 & 14 & 18 & 1.8 \\
\hline 15 & M & 5 & 29 & 5 & 27 & 11.2 \\
\hline 16 & $\mathrm{M}$ & 5 & 35 & 1 & 23 & 1.8 \\
\hline 17 & $\mathrm{~F}$ & 6 & 36 & 7 & 11 & 8.4 \\
\hline 18 & $F$ & 6 & 28 & 12 & 36 & 0.9 \\
\hline 19 & $F$ & 6 & 40 & 8 & 19 & 2.7 \\
\hline 20 & $\mathrm{~F}$ & 6 & 17 & 1 & 10 & 4.2 \\
\hline 21 & $\mathrm{~F}$ & 7 & 30 & 18 & 16 & 1.6 \\
\hline 22 & $F$ & 7 & 20 & 3 & 14 & 0.7 \\
\hline \multirow[t]{2}{*}{23} & M & 8 & 58 & 3 & 35 & 2.2 \\
\hline & MEAN & & $\begin{array}{c}37.8, \mathrm{SD} \\
13.4\end{array}$ & $\begin{array}{c}7.4, \text { SD } \\
4.9\end{array}$ & $\begin{array}{l}24.6, \mathrm{SD} \\
10.3\end{array}$ & $\begin{array}{c}2.5, \mathrm{SD} \\
2.6\end{array}$ \\
\hline
\end{tabular}

tions. Four individuals at risk who developed minor signs not considered in these data, also had low GDH activity, while two other family members without any symptoms had normal values.

\section{Discussion}

A partial deficiency of GDH activity in fibroblasts, leukocytes or platelets from patients with different forms of spinocerebellar degeneration has been reported. ${ }^{11-13,16-21,26-36}$ Most of the populations studied are heterogeneous both clinically and genetically. These facts make it impossible to compare some of the results. In our study all the patients had a dominant form of ataxia. Despite some clinical heterogeneity, they all had the same disorder - Machado-Joseph disease. There was a significant decrease of GDH activity in the patient group as previously reported by Sudarsky et al. ${ }^{28}$ in the same disorder. The exact meaning of this deficiency is not known but it may be a secondary phenomenon related to altered mitochondrial metabolism. ${ }^{33}$ Also unknown is the significance of the unusually high GDH levels found in two patients. In patient 15 it could be related to alcohol consumption since high GDH activity has been described in patients with alcoholic ataxia. ${ }^{36}$ Patient 17 has associated idiopathic parkinsonism under therapy, probably affecting GDH activity. Our data confirm and extend previous reports indicating that GDH deficiency could be present in peripheral tissues from some patients with dominant ataxia. However this deficiency is not specific for an autosomal dominant inheritance since it has been found in other forms of ataxia as well as other degenerative neurological disorders.

The real significance of the decrease of GDH activity is unknown and, as suggested by Finochiaro et al.," GDH deficiency may not be an expression of a primary gene defect but an epiphenomenon of hereditary ataxias. Despite this controversy about the significance of low GDH activities in spinocerebellar degenerations, its presence in some forms of ataxia is generally accepted and it is possible to identify two different forms of this enzyme. Plaitakis et al ${ }^{29}$ have fractionated leukocyte GDH into "particulate heat-labile" and "soluble heat-stable" components. They concluded from heat inactivation studies that the defect was only in the "heat-labile particulate" fraction. Similar results have been reported in patients with OPCA ${ }^{21}$ and sporadic ataxia. ${ }^{36}$

The role of GDH deficiency in the pathogenesis of degenerative ataxic disorders was initially attributed to increased levels of glutamate and consequent excitotoxic degeneration of cerebellar neurons. This hypothesis was supported by some experimental issues. The nicotinamide antagonist 3-acetylpyridine has been shown to produce morphological changes in experimental animals resembling those of OPCA. This toxic agent can form abnormal nucleotides which inhibit the required nicotinamide adenine dinucleotide phosphate (NADP) leading to degeneration of neuronal systems sensitive to that inhibition. ${ }^{26}$ This finding encouraged preliminary studies on the possible role of GDH deficiency in the pathogenesis of the ataxic syndromes. Deficiency of GDH activity might be responsible for decreased glutamate catabolism in some patients with multiple system atrophies. The accumulation of glutamate in some regions of the nervous system could be the cause of the neuronal degeneration as a consequence of excessive firing of glutamatergic neurons ${ }^{27}$ or decreased intracellular glutathione levels leading to increased sensitivity of cells to peroxidative damage. ${ }^{29}$ However, it cannot be excluded that alterations of GDH activity could go along with a decrease of glutamate content in specific neuronal groups with consequent low activity and progressive atrophy in selected areas of the nervous system. ${ }^{11}$ 
More recent studies showed no significant differences from controls in GDH activity in brain homogenates from patients with ataxia obtained at necropsy. Grossman et al. ${ }^{37}$ and Rosenberg and Banner ${ }^{38}$ reported normal mitochondrial and cytosolic GDH activity in cerebellar and cerebral cortical samples from patients with dominant OPCA and Machado-Joseph disease. Chokroverty et al. ${ }^{39}$ found normal levels of GDH activity in brain samples from a patient with OPCA and reduced leukocytic activity. These results indicate that peripheral GDH deficiency does not correlate with brain GDH activity and may not be involved in the pathogenesis of these disorders. Further studies are necessary to elucidate the exact meaning of these abnormalities in the ataxic syndromes as well as its importance in risk prediction of the disease.

\section{ACKNOWLEDGEMEN"}

The authors are thankful to Drs. P. Ferreira and M. Viegas for statistical assistance and $M$. Helena for technical assistance. The work was supported in part by the Secretaria Regional dos Assuntos Sociais, Azores.

\section{REFERENCES}

1. Harding $A$. The hereditary ataxias and related disorders. In: Glaser G, Barbeau A, Barnett H, Collins W, eds. Clinical Neurology and Neurosurgery Monographs. Vol. 6. Churchill Livingstone 1984.

2. Blass J. Hereditary ataxias. In: Current Neurology. John Wiley and Sons, eds., New York 1981: 66-91.

3. Perry T, Currier O, Hansen S, MacLean J. Aspartate-taurine imbalance in dominantly inherited olivopontocerebellar atrophy. Neurology 1977; 27: 257-261.

4. Perry T, Hansen S, Currier R, Berry K. Abnormalities in neurotransmitter AA in dominantly inherited cerebellar disorders. In: Kark R, Rosenberg, R, Schut L, eds. Adv Neurol, Vol 21. The Inherited Ataxias. New York: Raven Press 1978: 303-314.

5. Perry T, Kish S, Hansen S, Currier R. Neurotransmitter AA in dominantly inherited cerebellar disorders. Neurology 1981; 31: 237242.

6. Perry T. Four biochemically different types of dominantly inherited OPCA. In: Duvoisin R, Plaitakis A, eds. Adv Neurol, Vol 41. The Olivopontocerebellar Atrophies. New York: Raven Press 1984; 205-216.

7. McGeer P, Eccles J, McGeer E. Putative excitatory neurons: glutamate and aspartate, In: McGeer P, Eccles J, McGeer E, eds. Molecular Neurobiology of the Mammalian Brain. New York: Plenum Press 1978; 183-197.

8. Engelsen B. Neurotransmitter glutamate: its clinical importance. Acta Neurol Scand 1986; 74: 337-355.

9. Prusiner S. Disorders of glutamate metabolism and neurological dysfunction. Ann Rev Med 1981; 32: 521-542.

10. Nicklas W. Amino acid metabolism in the central nervous system: role of glutamate dehydrogenase. In: Duvoisin R, Plaitakis A, eds. Adv Neurol, Vol 4l. The Olivopontocerebellar Atrophies. New York: Raven Press 1984; 245-253.

11. Finochiaro G, Taroni F, Di Donato S. GDH in OPCA: leucocytes, fibroblasts, and muscle mitochondria. Neurology 1986; 36: 550553.

12. Sorbi S, Piacentini S, Tonini S. Abnormal GDH activity and activation in dominant and recessive OPCA (abstract). Ann Neurol 1984: 16-136.

13. Sorbi S, Tonini S, Giannini E, et al. Abnormal platelet GDH activity and activation in dominant and nondominant OPCA. Ann Neurol 1986; 19: 239-245.

14. Barbeau A, Charbonneau M, Cloutier T. Leucocyte glutamate dehydrogenase in various hereditary ataxias. Can J Neurol Sci 1980; 7: 421-424.

15. Plaitakis A, Berl S, Nicklas W, Yahr M. Glutamate dehydrogenase deficiency in spinocerebellar degeneration: correlation with adult-onset recessive ataxia. Trans Am Neurol Assoc 1980; 105: 476-477.

16. Plaitakis A, Berl S, Yahr M. Neurological disorders associated with deficiency of GDH. Ann Neurol 1984; 15: 144-153.

17. Yamaguchi $T$, Hasashi $K$, Murakami $H$, et al. GDH deficiency in spinocerebellar degenerations. Neurochem Res 1982; 7: 627-636.

18. Maruyama S, Yamaguchi T. GDH and PDH deficiency in spinocerebellar atrophies. In: Duvoisin R, Plaitakis A, eds. Adv Neurol, Vol 41. New York: Raven Press 1984; 252-265.

19. Duvoisin R, Chokroverty S, Lepore F, Nicklas W. Glutamate dehydrogenase deficiency in patients with olivopontocerebellar atrophy. Neurology 1983; 33: 1322-1327.

20. Chokroverty S, Duvoisin R, Sachdev R, et al. Neurophysiologic study of OPCA with or without GDH deficiency. Neurology 1985; 35: 652-659.

21. Konagaya Y, Konagaya M, Takayanagi T. GDH and its isozyme activity in OPCA. J Neurol Sci 1986; 74: 231-236.

22. Cunha L, Gonçalves A, Dinis M, et al. Dominantly inherited ataxias in Portugal. Can J Neurol Sci 1988; 15: 397-401.

23. Christhlieb A, Sbarra A, Bardawil N. Isolation of highly purified, viable leucocytes from blood. Am J Clin Pathol 1962; 37: 257-262.

24. Layne E. Spectrophotometric and turbidimetric methods for measuring proteins. I $n$ : Colowick S, Kaplan N, eds. Methods in Enzymology, Vol 3. New York: Academic Press 1957; 447-454.

25. Lima L, Coutinho P. Clinical criteria for diagnosis of MachadoJoseph disease: report of a non-Azorean Portuguese family. Neurology 1980; 30: 319-322.

26. Plaitakis A, Nicklas W, Desnick R. GDH deficiency in three patients with spinocebellar syndrome. Ann Neurol 1980; 7: 297-303.

27. Plaitakis A, Berl S, Yahr M. Abnormal glutamate metabolism in an adult-onset degenerative neurological disorder. Science 1982; 216: 193-196.

28. Sudarsky L, Shin V, Mandell R. Reduced glutamate dehydrogenase activity in Joseph's disease. Neurology 1984; 34: 150.

29. Plaitakis A, Berl S, Yahr M. Neurological disorders associated with deficiency of GDH. Ann Neurol 1984; 15: 144-153.

30. Aubby D, Saggu H, Jenner P, et al. Leucocyte glutamate dehydrogenase activity in patients with degenerative neurological disorders. J Neurol Neurosurg Psychiatry 1988; 51: 893-902.

31. Kajiyama K, Neno S, Tatsumi T, et al. Decreased glutamate dehydrogenase protein in spinocerebellar degeneration. J Neurol Neurosurg Psychiatry 1988; 51: 1078-1080.

32. Duvoisin R, Nicklas W, Ritchie V, Sage J, Chokroverty S. Low leukocyte glutamate dehydrogenase activity do not correlate with a particular type of multiple system atrophy. J Neurol Neurosurg Psychiatry 1988; 51: 1508-1511.

33. Orsi L, Bertolotto A, Brignolio F, et al. Glutamate dehydrogenase (GDH) deficiency in different types of progressive hereditary cerebellar ataxia. Acta Neurol Scand 1988; 78: 394-400.

34. Tatsumi C, Yorifuji K, Kajiyma K, et al. Glutamate metabolism of leukocyes and skin fibroblasts in spinocerebellar degeneration with lowered glutamate dehydrogenase activity. Acta Neurol Scand 1989; 79: 465-468.

35. Sorbi S, Piacentini S, Fani C, et al. Abnormalities of mitochondrial enzymes in hereditary ataxias. Acta Neurol Scand 1989; 80: 103110.

36. Kaakkola S, Marnela K-M, Oja S, et al. Leukocyte glutamate dehydrogenase and CSF amino acids in late onset ataxias. Acta Neurol Scand 1990; 82: 225-229.

37. Grossman A, Rosenberg R, Warmoth L. Glutamate and malate dehydrogenase activities in Joseph disease and olivopontocerebellar atrophy. Neurology 1987; 37: 106-111.

38. Rosenberg R, Banner C. Normal cerebellar glutamate dehydrogenase protein in spinocerebellar degeneration. $\mathbf{J}$ Neurol Neurosurg Psychiatry 1989; 52: 666-668.

39. Chokroverty S, Nicklas W, Miller D, et al. Multiple system degeneration with glutamate dehydrogenase deficiency: pathology and biochemistry. J Neurol Neurosurg Psychiatry 1990; 53: 1099. 1101 . 